\title{
Combined Cutting-deforming Taps
}

\author{
Irina Stefanova Aleksandrova* - Gancho Nenkov Ganev \\ Technical University of Gabrovo, Bulgaria
}

Enhancement of the efficiency and quality of internal thread forming requires continuous improvements in the design of the tools used and optimization of their body geometry. A new design for cutting-tightening taps with enhanced strength and reliability for forming thread surfaces by combining the methods of cutting and plastic deformation are proposed in this paper. An experimental study of torque was carried out during thread forming employing the designed combined tool and the major factors having an effect on the tool serviceability were defined. An algorithm for designing cutting-tightening taps has been proposed, which guarantees a minimum torque in thread forming.

Keywords: threads, methods of machining, combined cutting-deforming tap

\section{INTRODUCTION}

Quality parameters of threads when machining depend both on material properties and on a number of technological factors: method and arrangement of shape-forming, tool structure and geometry, as well as cutting conditions [1] to [10]. The technology employed for making threaded parts has to provide a set of geometrical parameters and characteristics of the state of the surface layer, thus determining the performance characteristics of the threaded connection dependent on its functional purpose.

Thread surfaces - external or internal - are obtained by three principal methods: cutting, plastic working, and a combined method [2] to [5], [7], [8], and [11] to [15]. The two latter methods have a number of advantages as regards guaranteeing the major quality characteristics of all types of threaded connections. This is attributed to the greater hardness of the surface layer of the thread turns, the positive effect of surface compressive stresses, stable high accuracy, and low roughness of surfaces.

The use of combined machining and plastic deformation of external threads is widespread and is the prevailing method used for a number of fastener threaded parts [8]. For internal threads, having lower manufacturing producibility, these working methods, regardless of their obvious advantages, find limited application.

It is known that over $60 \%$ of the parts of modern machines and mechanisms have threaded holes. Making internal threads, especially of small sizes, is a manufacturing problem, owing to the insufficient strength and reliability of the tools (taps) used. The design and use of new tool materials, the application of optimum technological equipment and new kinds of lubricating-cooling agents do not solve the problems of highly productive, quality manufacturing of internal threads. Continuous improvement in tap design, geometry optimization of tap bodies, and improvement of manufacturing technology of taps is necessary, since these are the most widely used tools for machining internal threads.

The objective of this paper is the structural and technological development and experimental study of a new design of cutting-deforming taps which have enhanced strength and reliability, combining both methods of formation - cutting and plastic deformation. By creating these taps, opportunities are offered for intensifying the internal thread forming process accompanied by quality improvement. The objective of this paper has been formulated on the basis of comparison, analysis and quality evaluation of advantages and disadvantages of methods and tools for making internal threads with diameters ranging from 1 to $16 \mathrm{~mm}$ (Table 1 ).

\section{DESIGN AND STUDY OF COMBINED CUTTING-DEFORMING TAPS}

\subsection{Analysis of the Possibilities for Enhancing the Strength of Taps}

In order to determine tap, it is necessary to take into account the shape and size of the operating tool elements as a geometric body, as well as the size and character of change in the forces affecting tool wear.

During internal thread forming, taps are mainly subjected to torsional loads and sometimes to bending loads (when the hole and tool axes are displaced). Therefore, tangential stresses are most dangerous for taps occurring where the tool tends to be twisted by the applied torque. The destruction (breaking) of these tools depends mainly on the size of the maximum torque and on their cross-section.

To determine the size of the crushing torque, special test specimens of high-speed steel HSS with a hardness of HRC 63 were made. One of the specimens has a cross-section of three-sided relieved profile of chipless tap with an M8 ground thread with the 
following dimensions: inside diameter $d_{1}=6.65 \mathrm{~mm}$; outside diameter $d=8.144 \mathrm{~mm}$; mean diameter $d_{2}=$ $7.30 \mathrm{~mm}$; height of relieving $k=0.48 \mathrm{~mm}$. The crosssection of the test specimen is $S_{n_{1}}=29.175 \mathrm{~mm}^{2}$; and it is determined according to the relationship [4]:

$$
S_{n_{1}}=\frac{\left(d_{1}-k\right)^{2} \pi}{4}-A k^{2} \pi,
$$

where $A=1$ is a constant for the three-sided relieved tap.

Table 1. Quality evaluation of methods and tools for cutting internal threads

\begin{tabular}{lll}
\hline Parameters & Tapping & $\begin{array}{l}\text { Threading with fluteless taps } \\
\text { (by plastic deformation) }\end{array}$ \\
\hline $\begin{array}{l}\text { Geometric accuracy } \\
\text { of thread }\end{array}$ & satisfactory & good \\
\hline $\begin{array}{l}\text { Degree of roughness } \\
\text { of thread }\end{array}$ & satisfactory & good \\
\hline $\begin{array}{l}\text { Strength properties } \\
\text { of threads }\end{array}$ & satisfactory & good \\
\hline $\begin{array}{l}\text { Applicability to } \\
\text { various materials }\end{array}$ & good & low (for working metals with \\
\hline $\begin{array}{l}\text { Manufacturing } \\
\text { producibility of tool }\end{array}$ & good & satisfactory \\
\hline Output & low & good \\
\hline $\begin{array}{l}\text { Tool life } \\
\text { Strength of the } \\
\text { bearing section of } \\
\text { the tool }\end{array}$ & low & satisfactory \\
\hline
\end{tabular}

The second specimen is a conventional M8 thread-cutting tap. Due to the complicated profile of the cross-section of the thread-cutting taps, universally valid formulae for calculating its area are not available in literature. However, the area can be determined graphically in the AutoCAD environment and it is $S_{n_{2}}=10.2 \mathrm{~mm}^{2}$.

After loading the test specimens the following results were obtained for the breaking torque $M_{d}$ and failure tangential stresses $\tau$ :

- for the chipless specimen M8; $M_{d_{1}}=65.6 \mathrm{Nm}$; $\tau_{1}=670 \mathrm{MPa}$;

- for specimen M8 with chip flutes; $M_{d_{2}}=21.7 \mathrm{Nm}$; $\tau_{2}=640 \mathrm{MPa}$.

The relationship between the determined values of the breaking torques for chipless and thread-cutting taps characterizes the common safety margin (Eq. 2), since the determined values for failure stresses were approximately identical:

$$
K_{S}=\frac{M_{d_{1}}}{M_{d_{2}}}=\frac{65.6}{21.7}=3.023 .
$$

The analysis made shows that the chipless tap is over three times stronger than the conventional thread-cutting tap. This led us to the idea of designing a tap with a forming part, which encloses a cutting part that removes the whole or most of the additive as in conventional thread-cutting taps, and a tightening part, which through plastic deformation finishes and strengthens the thread. The calibrating part of the tap is shaped as chipless fluteless taps and thus the tool strength is significantly enhanced.

\subsection{Design of Thread-tightening Taps with Enhanced Strength}

In accordance with the theoretical-experimental anlaysis, a combined cutting-deforming (threadtightening) tap was designed, which encloses a forming part that has a length of $l_{f}$ and a calibrating part. The cross-sections of the forming and calibrating parts are shaped and relieved as chipless taps (Section e-e) (Table 2), which enhances the tool strength. On the front part of the tap at length $l_{s}$, a certain number of chip flutes with the geometry required for cutting are made. The forming part $\left(l_{f}\right)$ of the tap consists of two zones: cutting - having a length of $l_{c}$ and tightening - having a length of $l_{d}$, shaped at angles $\chi_{r_{1}}$ and $\chi_{r}$ respectively, where $\chi_{r_{1}} \geq \chi_{r}$ (Table 2). The lengths of the cutting and tightening parts are determined by the location of point $T$ (the point where the chip flute inclined at angle $\lambda$ intersects the axial plane of the tap) and by the length of the forming part, $l_{f}$. The teeth positioned in front of point $T$ (Section a-a) are cutting with a positive clearance angle defined by the relieving on the flank. The teeth positioned after point $T$ (Section $\mathrm{b}-\mathrm{b}$ ), are tightening owing to their negative clearance angle shaped by the rising slope of the relieving curve of the preceding tooth of the tap.

Depending on the position and length of the chip flutes with regard to the forming part with length $l_{f}$ and the size of angle $\lambda$, various arrangements are possible (Table 2), which define the tap as cutting or cutting-tightening.

\subsubsection{Taps with Inclined Chip Flutes $\lambda>0^{\circ}$ and Variable Rake $\gamma$ along the Chip Flute}

If $l_{f} \geq l_{c}$ and diameter $d_{0}$ of the preliminary drilled hole is within: $d_{2} \geq d_{0} \geq d_{1}$, the tap is cutting-tightening. For thread diameters less than $d_{T}$ (Table 2), the tap is cutting.

If $l_{f}<l_{c}$, the tap is cutting and part of the calibrating teeth is also cutting. The tool differs from conventional cutting taps mainly in that there are no 
chip flutes on its calibrating part, which significantly enhances its strength and reduces the chance of breaking.

\subsubsection{Taps with Straight Chip Flutes $\left(\lambda=0^{\circ}\right)$ and Invariable Rake along the Chip Flute}

If $l_{c}=l_{s} \leq l_{f}$ and diameter $d_{0}$ of the preliminary drilled hole is within: $d_{2} \geq d_{0} \geq d_{1}$, the tap is cutting-tightening.
The cutting part with angle $\chi_{r_{1}}$ is additionally relieved (Section f-f, Table 2).

If $l_{c}=l_{s}>l_{f}$, the tap is cutting.

\subsection{Experimental Study of the Designed Thread-tightening Taps}

The internal thread forming process employing the designed cutting-deforming taps and their

Table 2. Taps - geometrical and structural elements

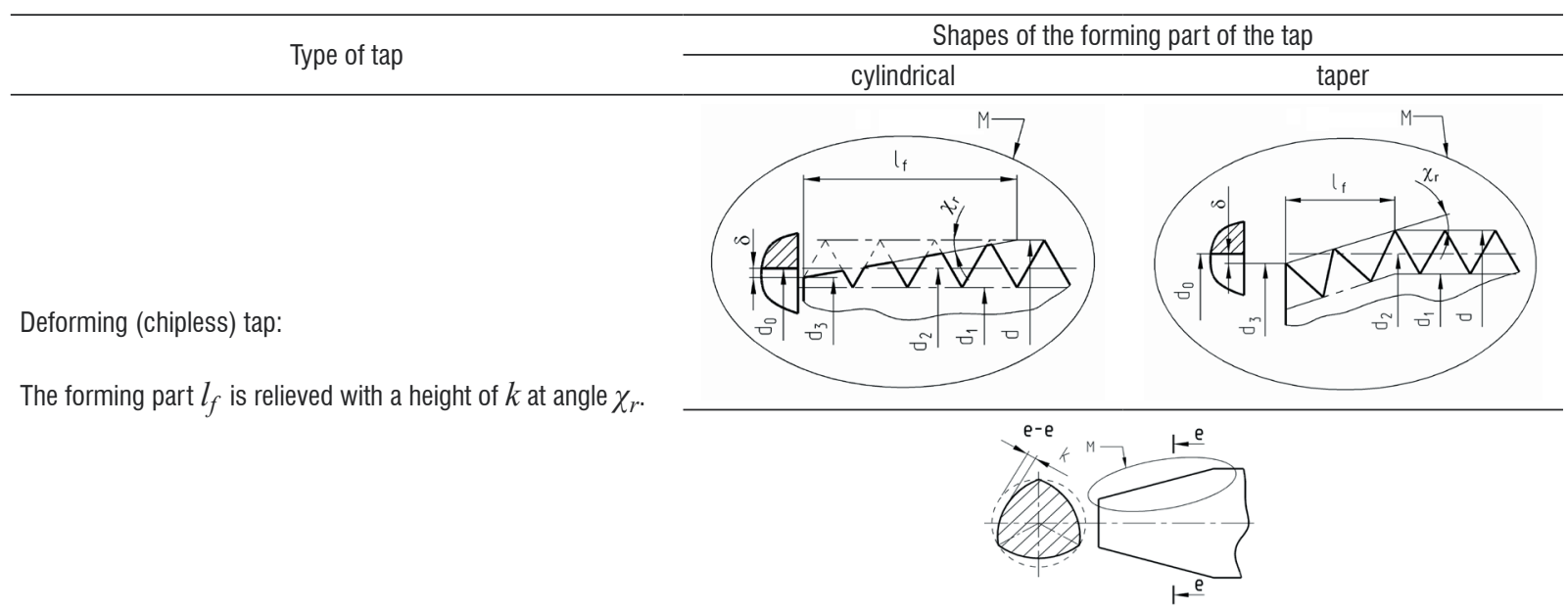

Inclined chip flutes at angle $\lambda>0^{\circ}$

Cutting-deforming tap:

- $l_{c} \leq l_{f} ; d_{2} \geq d_{0} \geq d_{1} ; d_{3}=d_{0}-\delta$;

- angle $\gamma$ is variable $(\gamma \geq 0)$ for the forming part $l_{f}$.
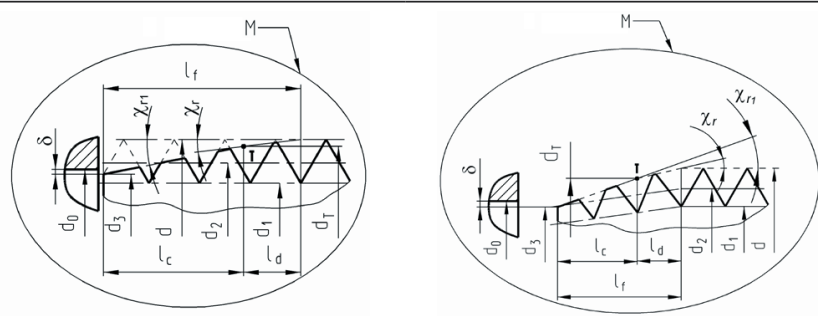

Cutting tap:

- $l_{c}>l_{f} ; d_{3}=d_{0}-\delta$;

- angle $\gamma$ is variable: $\gamma=\arcsin \frac{2 a_{i}}{d_{i}}$.

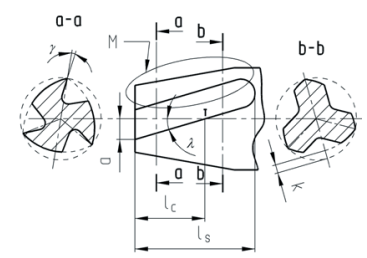

Straight chip flutes $\left(\lambda=0^{\circ}\right)$

Cutting-deforming tap:

- $l_{c} \leq l_{f} ; d_{2} \geq d_{0} \geq d_{1}$;

- cutting part $l_{c}$ is relieved with a height of $k$ at angle $\chi_{r_{1}}$;

- tightening part $l_{d}$ is relieved with a height of $k$ at angle $\chi_{r}$.

Cutting tap:

- $l_{c} \geq l_{f} ; d_{0} \geq d_{1} ; d_{3}=d_{0}-\delta$;

- cutting part $l_{c}$ is relieved with a height of $k$ at angle $\chi_{r_{1}}$;

- chip flute length $l_{s} \geq l_{f}$.

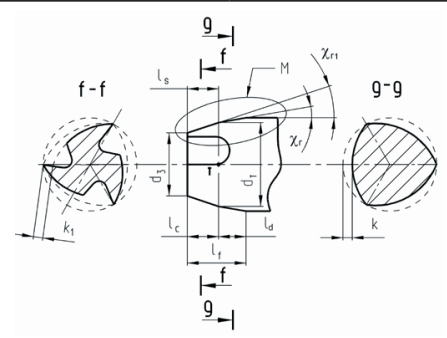


serviceability depend on a great number of factors, which can be divided into two large groups:

- Factors determined by the tool structure: pitch $p$ and diameter $d$ of the thread, lengths of cutting and tightening parts $l_{c}$ and $l_{d}$, number of flutes, geometrical elements of the forming part (inclination angle of the chip flute $\lambda$, rake angle $\gamma$, clearance angle $\alpha$, angles of cutting and tightening parts $\chi_{r_{1}}$ and $\chi_{r}$ ), and the arrangement for manufacturing the forming part;

- Factors determined by the type of machining: material to be machined (hardness, chemical composition, and structure), thread length, type of hole - blind or through, diameter of the preliminary drilled hole $d_{0}$, plastic deformation additives vs. cutting additives ratio ( $\eta[\%])$, lubricating-cooling liquid type, intensity and feeding method in the cutting zone, machining conditions, etc.

Preliminary experimental studies of the serviceability of the designed cutting-deforming tap have been conducted. The maximum torque $M_{b_{\max }}$ in thread forming is taken to be a parameter for evaluating serviceability. For strength reasons, $M_{b_{\max }}$ should be deliberately kept at a minimum, especially if taking into account that the cross-section of the tap is limited by the thread diameter.

Four thread-tightening taps M8 with three flutes $(z=3)$ of high-speed steel HSS have been made for conducting the study. Their design parameters are listed in Table 3.

The studied taps operate under identical conditions and the ratio of additives for plastic deformation to additives for cutting is (Table 2, Table 3):

$$
\eta=\left(\frac{d-d_{T}}{d-d_{2}}\right)^{2} 100=17.5 \%
$$

Table 3. Experimental conditions

\begin{tabular}{ccccc}
\hline No. & $\lambda[\mathrm{grad}]$ & $l_{c}[\mathrm{~mm}]$ & $\chi_{r}$ [grad $]$ & $\chi_{r_{1}}$ [grad $]$ \\
\hline 1 & 0 & 10.5 & 2 & 2.45 \\
\hline 2 & 3 & 10.05 & 2 & 2.54 \\
\hline 3 & 6 & 5.7 & 2 & 4.5 \\
\hline 4 & 9 & 3.8 & 2 & 6.76 \\
\hline$d=8.144_{-0.02} \mathrm{~mm} ; d_{2}=7.323_{-0.02} \mathrm{~mm} ; d_{3}=6.9 \mathrm{~mm} ;$ \\
$\gamma_{\max }=10^{\circ} ; k=0.48 \mathrm{~mm} ; d_{0}=7^{+0.03} \mathrm{~mm} ; d_{T}=7.8 \mathrm{~mm} ;$ \\
$l_{\mathrm{c}}=\frac{d_{3} \sin \gamma_{\max }}{2 \operatorname{tg} \lambda}\left(\lambda>0^{\circ}\right)$ \\
$\chi_{\mathrm{r}_{1}}=\operatorname{arctg}\left[\frac{\left(2 d_{\mathrm{T}}-d-d_{1}\right) \operatorname{tg} \lambda}{\left(d+d_{1}-d_{\mathrm{T}}\right) \sin \gamma_{\max }}\right]$.
\end{tabular}

The material machined is steel C45 and Castrol Carecut ES1 thread oil was used as a lubricatingcooling liquid. The length and diameter of the through holes being worked are respectively: $l_{0}=13 \mathrm{~mm}$; and $d_{0}=7^{+0.03} \mathrm{~mm}$. The torque is measured at a purpose stand for torque testing Microtap at constant speed of rotation $n=315 \mathrm{~min}^{-1}$.

Four experiments were conducted and during each experiment four observations were made. The character of the torque variations at $\lambda=0^{\circ}$ is shown in Fig. 1, and at $\lambda>0^{\circ}$ in Fig. 2. The measured values of maximum torque $M_{b_{\max }}$ are presented in Table 4.

The analysis of the experimental results obtained shows that the magnitude of the maximum torque during thread forming depends on the length of the cutting part of the designed thread-deforming tap and that $M_{b_{\max }}$ decreases as the length increases. This

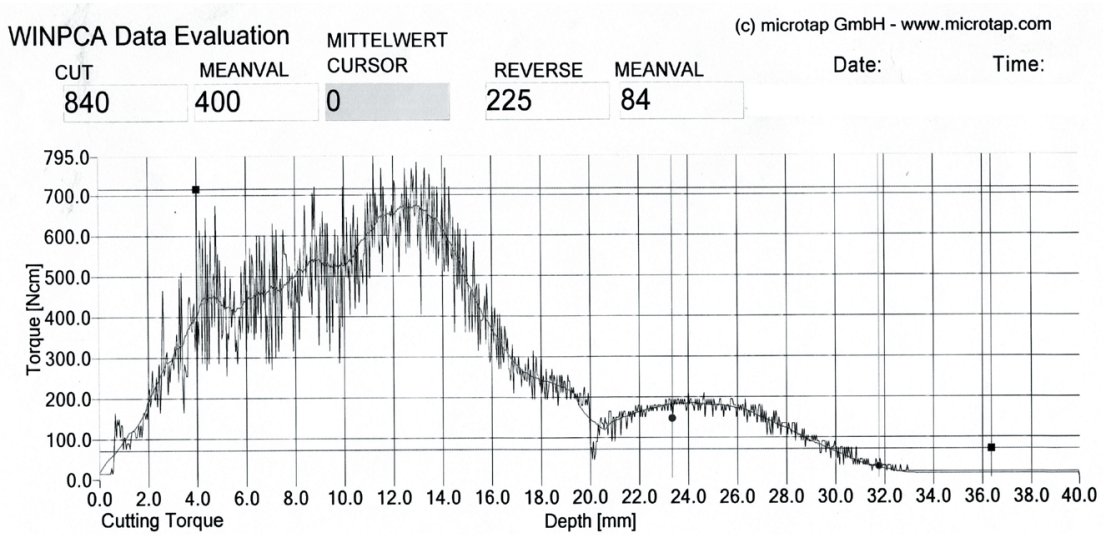

Fig. 1. Torque during working with thread-tightening taps with straight chip flutes $\left(\lambda=0^{\circ}\right)$ 
is explained by the increasing thickness of the layer being cut $h_{z}$ by one cutting tooth:

$$
h_{\mathrm{z}}=\frac{\left(d_{\mathrm{T}}-d_{3}\right) p}{2 l_{\mathrm{c}} z}=(0.0178 \div 0.0493) \mathrm{mm} \text {. }
$$

Therefore, when the ratio of additives for plastic deformation to additives for cutting $\eta$ is set, it is necessary for the length of the cutting part of the tap to be at a maximum.

Table 4. Experimental results

\begin{tabular}{|c|c|c|c|c|}
\hline \multirow{2}{*}{$n$} & \multicolumn{4}{|c|}{$M_{b_{\max }}[\mathrm{Nm}]$} \\
\cline { 2 - 5 } & $\lambda=0^{\circ}$ & $\lambda=3^{\circ}$ & $\lambda=6^{\circ}$ & $\lambda=9^{\circ}$ \\
\hline 1 & 7.80 & 8.25 & 9.75 & 17.55 \\
\hline 2 & 9.60 & 8.40 & 12.55 & 18.15 \\
\hline 3 & 8.40 & 7.65 & 13.95 & 16.65 \\
\hline 4 & 6.00 & 9.00 & 12.90 & 17.25 \\
\hline $\bar{M}_{b_{\max }}$ & 7.95 & 8.33 & 12.28 & 17.4 \\
\hline
\end{tabular}

The algorithm of designing cutting-tightening taps is the following:

1. The ratio of additives for plastic deformation and additives for cutting is assumed to be $\eta[\%]$.
2. The diameter $d_{T}=d-0.1 \sqrt{\eta\left(d-d_{2}\right)}$ is determined (Table 2).

3. The diameter of the preliminary drilled hole $d_{0}=d+d_{1}-d_{T}$ is determined.

4. The diameter of the tap front $d_{3}=d_{0}-(0.05 \div 0.1)$ is determined.

5. The length of the cutting part $l_{c}=\frac{d_{T}-d_{3}}{2 \operatorname{tg} \chi_{r_{1}}} \rightarrow \max$ is determined, i.e. the cutting part angle $\chi_{r_{1}}$ should be as small as possible.

\section{CONCLUSION}

The possibility of increasing tap strength by designing combined tools with enhanced strength and reliability, and forming thread surfaces by combining the methods of both cutting and plastic deformation, has been backed by theoretical and experimental arguments. A new combined cuttingdeforming tap has been designed. Its forming part encloses two zones: a cutting zone, which removes the larger part of the additive as conventional thread cutting taps do, and a tightening zone, which by

a)
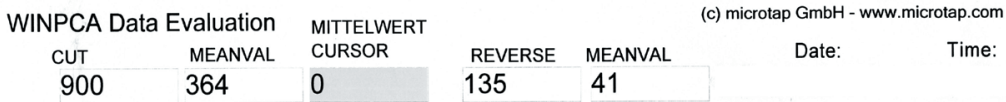

900

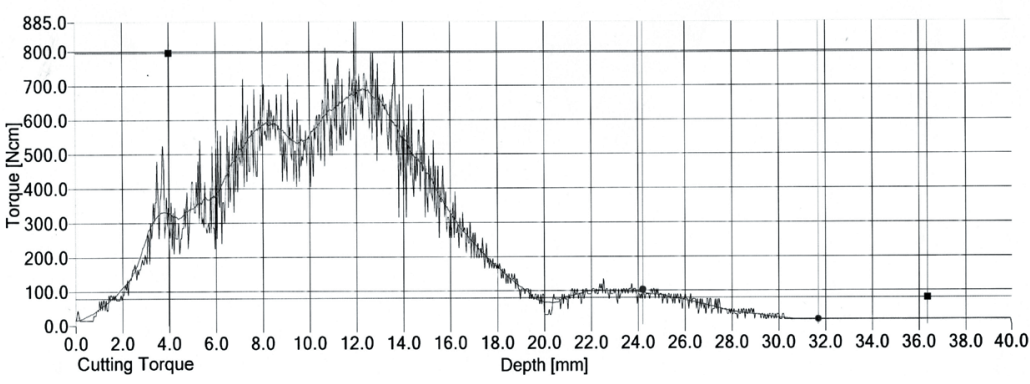

$\begin{array}{ccl}\text { WINPCA Data Evaluation } & \text { MITTELWERT } \\ \text { CUT } & \text { MEANVAL } & \text { CURSOR } \\ \text { C75 } & 467 & 0\end{array}$

$975-467$

0

REVERSE MEANVAL

(c) microtap GmbH - www. microtap.com

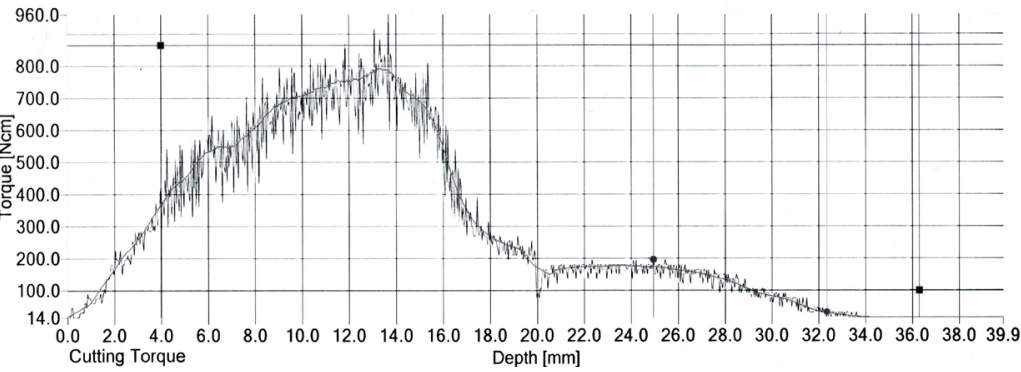

b)

Depth [mm]

Fig. 2. Torque during working with thread-tightening taps with inclined chip flutes: a) $\lambda=3^{\circ}$; $\left.b\right) \lambda=6^{\circ}$ 
plastic deformation further forms and strengthens the thread. The cross-sections of the forming and calibrating parts are shaped and relieved as chipless taps and that significantly enhances the tool strength, creating the conditions needed to enhance the quality of the machined thread. The expected higher quality is related to the fact that the final thread forming, which determines its accuracy and roughness, is achieved by plastic deformation and depends primarily on the manufacturing technology of the tap and its accuracy.

An experimental study of the torque when forming the thread employing the designed combined cutting-deforming taps has been conducted and the major factors having an effect on their serviceability have been defined.

An algorithm for designing cutting-tightening taps has been proposed that ensures minimum torque while forming the thread.

\section{REFERENCES}

[1] Andonov, I. (2001). Material Cutting. Softtrade, Sofia. (in Bulgarian)

[2] Ivanov, V. (1983). Chipless Taps - Design, Technology and Exploitation. $\mathrm{PhD}$ thesis. Rousse University Printing, Rousse. (in Bulgarian)

[3] Ivanov, V. (1998). Cutting Tools. Rousse University Printing, Rousse. (in Bulgarian)

[4] Menshakov V., Urlapov, G., Sereda, V. (1976). Chipless Taps. Mashinostroenie, Moscow. (in Russian)

[5] Prokofev, A. (2000). Progressive Technological Methods of Enhancing Thread Connection Quality. Reference Book. Engineering Journal, vol. 35, no. 2, p. 9-12. (in Russian)

[6] Prokofev, A. (2006). Technological equipment for obtaining performance properties of thread connections. In: Suslov, A., Fedorov, V., Gorlenko, O. et al. Technological Equipment and Enhancing Performance Properties of Parts and Their Connections, Mashinostroenie, Moscow, p. 334-394. (in Russian)
[7] Prokofev, A. (2008). Technological Equipment and Enhancing Performance Properties of Thread Connections, PhD Thesis. Bryansk State Technical University, Bryansk. (in Russian)

[8] Suslov, A. (1999). Development of scientific bases of working high-accuracy internal threads. In: Suslov, A., Steshkov, A., Prokofev, A. (ed.). Present Problems of Quality Enhancement of Mechanical Engineering Production, p. 128-129. (in Russian)

[9] Olinda de Carvalho, A. Brandão, L., Panzera, T., Lauro, C. (2012). Analysis of form threads using fluteless taps in cast magnesium alloy (AM60). Journal of Materials Processing Technology, vol. 212, no. 8, p. 1753-1760, DOI:10.1016/j.jmatprotec.2012.03.018.

[10] Stéphan, P., Mathurin, F. Guillot, J. (2012). Experimental study of forming and tightening processes with thread forming screws. Journal of Materials Processing Technology, vol. 212, no. 4, p. 766-775, DOI:10.1016/j.jmatprotec.2011.10.029.

[11] Ivanov, V., Kirov, V. (1997). Rolling of Internal Threads: Part 1. Journal of Materials Processing Technology, vol. 72, p. 214-220.

[12] Niţu, E., Iordache, M., Marincei, L., Charpentier, I., Le Coz, G., Ferron, G., Ungureanu, I. (2011). FEmodeling of cold rolling by in-feed method of circular grooves. Strojniški vestnik - Journal of Mechanical Engineering, vol. 57, no. 9, p. 667-673, DOI:10.5545/ sv-jme.2010.244.

[13] Fromentin, G.G., Poulachon, A., Moisan, Julien, B., Giessler, J. (2005). Precision and surface integrity of threads obtained by form tapping. CIRP Annals Manufacturing Technology, vol. 54, no. 1, p. 519-522, DOI:10.1016/S0007-8506(07)60159-0.

[14] Fromentin, G., Bierla, A., Minfray, C., Poulachon, G. (2010). An experimental study on the effects of lubrication in form tapping. Tribology International, vol. 43, no. 9, p. 1726-1734, DOI:10.1016/j. triboint.2010.04.005.

[15] Bhowmick, S., Lukitsch, M., Alpas, A. (2010). Tapping of Al-Si alloys with diamond-like carbon coated tools and minimum quantity of lubrication. Journal of Materials Processing Technology, vol. 210, no. 15, p. 2142-2153, DOI:10.1016/j.jmatprotec.2010.07.032. 